TẠP CHÍ KHOA HỌC ĐẠI HỌC TÂN TRÀO
ISSS: 2354 - 1431
http://tckh.daihoctantrao.edu.vn/

\title{
GIẢI PHÁP HOÀN THIỆN CHÍNH SÁCH PHÁT TRIỂN NGUỒN NHÂN LỤC TẠI TỈNH PHÚ THỌ
}

\author{
Nguyễn Thị Thu Hà ${ }^{l}$, Nguyễn Mai Chinh ${ }^{2 *}$ \\ ${ }^{1}$ Học viện Hành chính Quốc gia \\ ${ }^{2}$ Đại học Tân Trào \\ *Email: maichinh1989@gmail.com
}

\section{Thông tin bài viết}

Ngày nhận bài:

$28 / 4 / 2020$

Ngày duyệt đăng:

20/9/2020

Từ khóa:

Nguồn nhân lụcc, Phú Tho, chính sách.

\section{Tóm tắt}

Với mong muốn cung cấp một nguồn nhân lực đáp ứng yêu cầu trong thời kỳ mới nên việc nghiên cứu Chính sách phát triển nguồn nhân lực đáp ứng nhu cầu cách mạng công nghiệp 4.0 là cần thiết, từ thực tiễn tỉnh Phú Thọ, tác giả đưa ra một bức tranh tổng thể về chính sách phát triển nguồn nhân lực tại Phú Thọ trong thời gian qua, đánh giá những tồn tại và tìm ra nguyên nhân của những hạn chế đó, qua đó đề xuất một số giải pháp nhằm thực hiện tốt chính sách phát triển nguồn nhân lực đáp ứng yêu cầu của cuộc cách mạng 4.0.

\section{Đặt vấn đề}

Nhân lực là nhân tố quyết định nhất đối với sự phát triển của mỗi quốc gia. Trình độ phát triển của nguồn nhân lực là một thước đo chủ yếu sự phát triển của các quốc gia. Vì vậy, các quốc gia trên thế giới đều rất coi trọng phát triển nguồn nhân lực. Trong thế kỷ XX, đã có những quốc gia nghèo tài nguyên thiên nhiên, nhưng do phát huy tốt nguồn nhân lực nên đã đạt được thành tựu phát triển kinh tế - xã hội, hoàn thành công nghiệp hoá và hiện đại hoá chỉ trong vài ba thập kỷ.

Trong thời gian qua, tỉnh Phú Thọ đã thực hiện tốt chính sách phát triển nguồn nhân lực nhằm xây dựng một lực lượng lao động có chất lượng cao đáp ứng nhu cầu ngày càng cao của thành phố nói riêng và của cả tỉnh nói chung, tuy nhiên, số lượng lao động chất lượng cao còn thiếu, tính chuyên nghiệp của đội ngũ công chức, viên chức chưa cao, chưa đáp ứng được nhu cầu phát triển của tỉnh nhà, tỷ lệ cán bộ có trình độ sau đại học còn thấp, chưa có những chuyên gia đầu ngành, cơ cấu nguồn nhân lực chưa hợp lý giữa cung và cầu dẫn đến sự lãng phí trong đào tạo.....

\section{Một số khái niệm liên quan}

\section{Nguồn nhân lục}

Theo PGS.TS. Phạm Minh Hạc: nguồn nhân lực là tổng thế các tiềm năng lao động của một nước hoặc một địa phương, tức nguồn lao động được chuẩn bị sẵn sàng tham gia một công việc lao động nào đó, tức là những người lao động có kỹ năng bằng con đường đáp ứng được yêu cầu của cơ chế chuyển đổi cơ cấu lao động, cơ cấu kinh tế theo hướng công nghiệp hóa, hiện đại hóa ${ }^{1}$.

\footnotetext{
${ }^{1}$ Phạm Minh Hạc (2003), Đi vào thế kỷ XXI phát triển nguồn nhân lực phục vụ công nghiệp hóa, hiện đại hóa đất nước,Hội thảo về phát triển nguồn nhân lực KX-05-11 tại thành phố Hồ Chí Minh ngày 22/3/2003.
} 
Theo định nghĩa của Liên Hiệp Quốc: nguồn nhân lực là tất cả những kiến thức, kỹ năng, kinh nghiệm, năng lực và tính sáng tạo của con người có quan hệ tới sự phát triển của mỗi cá nhân và của đất nước ${ }^{2}$.

Nguồn nhân lực là tổng thể sức dự trữ, những tiềm năng, những lực lượng thể hiện sức mạnh và sự tác động của con người trong việc cải tạo tự nhiên và cải tạo xã hội ${ }^{3}$.

\section{Phát triển nguồn nhân lục}

Theo Từ điển tiếng Việt: "Phát triển là biến đổi hoạc làm cho biến đổi theo chiều huớng tăng, tù it đến nhiều, hẹp đến rộng, thấp đến cao, đơn giản đến phưc tap". 4

Theo Tổ chức lao động quốc tế ILO: phát triển nguồn nhân lực bao hàm phạm vi rộng, không chỉ là sự chiếm lĩnh lành nghề hoặc vấn đề đào tạo nói chung, mà còn là sự phát triển năng lực và sử dụng năng lực đó vào việc làm có hiệu quả, cũng như thỏa mãn nghề nghiệp và cuộc sống cá nhân. ${ }^{5}$

Việt Nam cũng đưa ra quan điểm riêng của mình về phát triển nhân lực phù hợp với tình hình đất nước. Mục tiêu chiến lược của phát triển nguồn nhân lực Việt Nam là đáp ứng sự nghiệp CNH-HDH đất nước để đến năm 2020 nước ta cơ bản trở thành một nước công nghiệp. Tại Đại hội lần thứ IX của Đảng, đã định hướng cho phát triển nguồn nhân lực Việt Nam là: "Người lao động có trí tuệ cao, có tay nghề thành thạo, có phẩm chất tốt đẹp, được đào tạo và bồi dưỡng bởi một nền giáo dục tiên tiến gắn liền với một nền khoa học công nghệ".

\section{Chính sách phát triển nguồn nhân lục}

Chính sách phát triển nguồn nhân lực là một công cụ quan trọng của nhà nước trong việc tạo điều kiện và thúc đẩy sự phát triển của nguồn nhân lực. Mục tiêu hướng tới của các chính sách phát triển nguồn nhân lực là phải phát huy được nhân tố con người trên cơ sở đảm bảo công bằng, bình đẳng về quyền lợi, nghĩa vụ công dân, kết hợp tốt tăng trưởng kinh tế và tiến bộ xã hội; chú trọng nâng cao đời sống vật chất, đồng thời với đời sống tinh thần.

Chính sách phát triển nguồn nhân lực chính là sự

\footnotetext{
2 Văn Đình Tấn, Nguồn nhân lực trong công cuộc công nghiệp hóa - hiện đại hóa ở nước ta;

3 Trần Thị Tâm Đan, Tạp chí cộng sản số 5;

4 Từ điển tiếng việt, $\mathrm{NXb}$ thống kê,

5 Phát triển và quản lý nguồn nhân lực xã hội (2006), Nxb Tư pháp;
}

thể chế hóa các đường lối, chủ trương, nhiệm vụ của Đảng vào các văn bản pháp quy nhằm chăm $l o$, giáo dục công dân trở thành nguồn nhân lực chất lượng cao đáp ứng với thời kỳ công nghiệp 4.0, xây dựng và bảo vể tổ quốc, hội nhập quốc tế.

\section{Thực trạng nguồn nhân lực tại tỉnh Phú Thọ}

Thư nhất, quy mô và cơ cấu nguồn nhân lực

Theo số liệu thống kê đến năm 2017, dân số trong độ tuổi lao động của toàn tỉnh là 854,1 nghìn người, trong đó, số người đang làm việc là 743,8 nghìn người chiếm $54,2 \%$ dân số. Cơ cấu lao động 15 tuổi trở lên đang làm việc trong các khu vực kinh tế có sự chuyển dịch đáng kể và theo hướng tích cực trong những năm gần đây. Trong đó, cơ cấu lao động khu vực nông, lâm, thủy sản giảm từ khoảng 55\% năm 2014 xuống còn 48\% năm 2018, khu vực công nghiệp và xây dựng tăng từ trên $19 \%$ lên khoảng gần $23 \%$, khu vực dịch vụ tăng từ $25 \%$ lên gần $30 \%$. Tỷ lệ thất nghiệp của lao động trong độ đuổi khu vực thành thị giảm từ $4,8 \%$ xuống còn $4,4 \%$. Điều này phản ánh nguồn nhân lực của tỉnh Phú Thọ đang trên đà phát triển.

Sự xuất hiện của các doanh nghiệp trẻ được xem như là một nhân tố mới trong nguồn nhân lực. Đó là một nguồn nhân lực dồi dào của tỉnh, nếu biết khai thác, bồi dưỡng, sử dụng tốt sẽ giải quyết được nhiều vấn đề trọng đại trong phát triển kinh tế, xã hội.

Hiện nay, ở tỉnh Phú Thọ có quy mô dân số khá lớn nên số người trong độ tuổi lao động cao và tăng nhanh. Hàng năm có khoảng gần 2000 người bước vào độ tuổi lao động. Năm 2020 tỉnh sẽ có khoảng gần 750.000 người trong độ tuổi lao động, chiếm 62,8\% tổng dân số. Đây là cơ hội cho tỉnh Phú Thọ phát triển, tận dụng nguồn nhân lực vô cùng quý giá để phát triển kinh tế, thực hiện thắng lợi sự nghiệp $\mathrm{CNH}-\mathrm{HĐN}$ của tỉnh. Với nguồn lực dồi dào, việc thu hút đầu tư nước ngoài vào tỉnh sẽ thuận lợi hơn rất nhiều, nhiều dự án đầu tư cần nguồn nhân lực lớn đã được triển khai trên địa bàn tỉnh như cơ khí, tiêu dùng... giải quyết công ăn việc làm cho một lực lượng lớn lao động xã hội. Bên cạnh đó, tỉnh Phú Thọ cũng thực hiện việc xuất khẩu lao động. Đây là thời cơ tốt nhất cho nguồn nhân lực phát triển.

\section{Thư hai, chất lương nguồn nhân lực}

\section{* Trình độ văn hóa}

Trình độ văn hóa thể hiện trí thức, kiến thức khoa học, thể hiện khả năng nhận thức xã hội của mỗi cá nhân, là nền tảng ban đầu để tiếp thu những kiến thức mới, khả năng nắm bắt vấn đề cũng như thái độ và 
cách ứng xử của mỗi cá nhân trong quan hệ với người khác.

Nhìn chung, nguồn nhân lực tỉnh Phú Thọ có trình độ văn hóa tương đối đồng đều. Vì vậy, lãnh đạo tỉnh cần tiếp tục quan tâm tới việc bồi dưỡng nâng cao trình độ văn hóa hơn nữa cho đội ngũ lao động này để đào tạo, bồi dưỡng người lao động ở tỉnh Phú Thọ có tinh thần yêu nước, có trật tự và tôn trọng pháp luật, hiểu biết rõ và biết so sánh hiệu quả lợi ích có liên quan, biết thực hiện nghĩa vụ, có trách nhiệm với nhiệm vụ của mình, xây dựng nguồn nhân lực có trình độ văn hóa, có chuyên môn, có khả năng tích cực và biết cần, kiệm, liêm chính, có sức khỏe, có văn minh.

\section{* Các kỹ năng mềm}

Đa số lao động ở tỉnh Phú Thọ xuất thân từ nông thôn, đã quen với lối sản xuất nông nghiệp nên khi bước vào nền sản xuất công nghiệp, lao động chưa thích nghi ngay với môi trường làm việc mới. Do đó, trong giai đoạn đầu, việc chấp hành ý thức tổ chức kỷ luật, pháp luật lao động còn hạn chế, cần thời gian để thích nghi. Lực lượng này chủ yếu làm việc theo sự phân công của cấp trên. Khi có sự hướng dẫn thì họ luôn có tinh thần hợp tác, phối hợp để hoàn thành công việc được giao, đức tính của người lao động là cần cù, chịu khó.

Trong những năm gần đây, công tác tuyên truyền, công tác quản lý được tăng cường, hiểu biết và ý thức chấp hành pháp luật của người dân nói chung và người lao động nói riêng được nâng lên. Thói quen làm việc tuân thủ các quy định, quy chế làm việc, có kỷ luật đã có bước tiến bộ, đặc biệt trong các doanh nghiệp công nghiệp chế biến có quy mô lớn, doanh nghiệp có vốn đầu tư nước ngoài. Ngoài ra cùng với việc các doanh nghiệp không ngừng mở rộng sản xuất, đầu tư máy móc, trang thiết bị hiện đại, làm việc theo dây truyền, ca kíp... cộng với công tác giáo dục, áp dụng các quy trình quản lý chất lượng, quản lý lao động khoa học tiên tiến được quan tâm, coi trọng, góp phần nâng cao tình thần hợp tác, năng suất lao động, chất lượng công việc, sản phẩm được nâng lên.

\section{* Trình độ chuyên môn kỹ thuật}

Đến năm 2018 tỷ lệ lao động qua đào tạo đạt $55 \%$, trong đó đào tạo có bằng cấp, chứng chỉ đạt trên $24,4 \%$, cao hơn trung bình chung của cả nước. Chỉ tính từ năm 2013 đến nay đã có 179,2 nghìn người được đào tạo mới; 18,7 nghìn lượt cán bộ, công chức, viên chức, công nhân kỹ thuật đào tạo lại và bồi dưỡng nâng cao trình độ. Nhờ vậy, chất lượng nguồn nhân lực không ngừng được nâng lên, lao động có trình độ đại học và trên đại học đạt $9,1 \%$, cao đẳng $8,7 \%$.

Hiện nay, tỉnh Phú Thọ đã có gần 50 cơ sở đào tạo nghề với mạng lưới phủ kín khắp các huyện, thành, thị trong tỉnh. Các cơ sở đào tạo, dạy nghề từng bước được nâng cấp, mở rộng quy mô với trên 150 mã ngành nghề đào tạo, trong đó trên 40 mã đào tạo đại học.

Bên cạnh đó, tỉnh Phú Thọ đã ban hành nhiều chính sách đãi ngộ đối với cán bộ khoa học kỹ thuật, công nhân bậc cao, sinh viên tốt nghiệp loại giỏi về công tác tại tỉnh. Đồng thời tỉnh cũng có nhiều chính sách hỗ trợ cán bộ công chức, viên chức đi đào tạo nâng cao trình độ nghiệp vụ, chuyên môn. Trong 5 năm, đã có 59 cán bộ được đào tạo tiến sỹ, 343 cán bộ đi đào tạo thạc sỹ, hàng trăm cán bộ được cử đi đào tạo bác sỹ chuyên khoa I, II; thu hút được 17 thạc sỹ, 20 sinh viên tốt nghiệp trong nước và ngoài nước loại giỏi, xuất xắc về công tác tại tỉnh.

Đặc biệt, tỉnh Phú Thọ cũng vừa quyết định dành nguồn kinh phí lớn hỗ trợ đào tạo tiến sỹ y khoa cho bác sỹ đang công tác tại các cơ sở y tế công lập của tỉnh. Mỗi bác sỹ được cử đi học sẽ được hỗ trợ 300 triệu đồng/năm với thời gian 3 năm. Dự kiến từ nay đến năm 2020 tỉnh sẽ đào tạo 27 tiến sỹ y khoa để nâng cao chất lượng nguồn nhân lực cho ngành $\mathrm{y}$, đảm bảo đội ngũ cán bộ $\mathrm{y}$, bác sỹ có đủ về số lượng, chất lượng đáp ứng nhu cầu cần thiết.

Để phát triển nguồn nhân lực đáp ứng yêu cầu địa phương, tỉnh Phú Thọ đã đưa ra nhiều chính sách thu hút, đãi ngộ các chuyên gia, nhà khoa học, giáo viên có trình độ giáo sư, tiến sĩ, thạc sĩ, chuyên gia đầu ngành, thợ bậc cao về giảng dạy và làm việc tại tỉnh. Xây dựng đội ngũ giáo viên, giảng viên đạt chuẩn về trình độ chuyên môn, có tinh thần trách nhiệm và đạo đức nghề nghiệp; bảo đảm chế độ chính sách cho đội ngũ giáo viên và người học theo quy định của Nhà nước. Nâng cao hiệu quả hoạt động hướng nghiệp trong các trường trung học cơ sở, trung học phổ thông và các cơ sở dạy nghề để giúp học sinh định hướng nghề nghiệp trong tương lai.

Tỉnh Phú Thọ đã và đang từng bước phát triển, từng bước tiến vào hội nhập, từng bước tiếp cận khoa học công nghệ, vì thế đòi hỏi một lực lượng đông đảo nhân lực có trình độ cao, có khả năng làm việc trong môi trường công nghệ và cạnh tranh. Đặc biệt với một số ngành đặc thù như công nghệ thông tin lại càng đòi hỏi nhân lực đạt đến trình độ quốc tế hóa. Bên cạnh đó, một số ngành mũi nhọn của tỉnh như 
nông nghiệp, du lịch, công nghiệp cũng yêu cầu đội ngũ đủ khả năng thích ứng với mọi sự biến động của môi trường trong nước và thế giới. Có thể nói rằng, ở lĩnh vực nào thì tỉnh Phú Thọ cũng đều đang thiếu lực lượng lao động chất lương cao. Thực tế hiện nay ở địa phương lực lượng lao động sản xuất nông nghiệp thiếu khoa học kỹ thuật, sản xuất manh mún. Lực lượng công nhân trình độ thấp. Hàng năm lượng sinh viên ra trường lớn nhưng số lượng sinh viên có việc làm còn thấp. Tỷ lệ sinh viên có việc làm không đúng ngành nghề còn cao.

\section{Hạn chế, nguyên nhân và một số giải pháp nhằm hoàn thiện chính sách phát triển nguồn nhân lực tại tỉnh Phú Thọ trong thời gian tới}

\subsection{Hạn chế}

Bên cạnh các kết quả đạt được, các chính sách phát triển nguồn nhân lực ở tỉnh Phú Thọ hiện nay còn bộc lộ một số hạn chế sau:

Một là, các văn bản dưới luật, cơ chế, chính sách về phát triển nguồn nhân lực chưa đồng bộ và chưa đáp ứng nhu cầu đổi mới. Nhiều chủ trương, chính sách chưa được thể chế hóa và cụ thể hóa bằng các chính sách cụ thể ở cấp vĩ mô, cấp ngành phù hợp nền kinh tế chuyển đổi. Nhiều vấn đề mới phát sinh và cũng có nhiều vấn đề bức xúc trong thực tiễn chưa được nhận thức thống nhất và giải đáp về mặt lý luận, nên khó khăn trong việc cụ thể hóa thành cơ chế, chính sách như là một công cụ quản lý trong điều kiện mới.

Hai là, quản lý chất lượng nguồn nhân lực là một trong những vấn đề khó khăn nhất hiện nay ở tỉnh Phú Thọ. Thực tế chất lượng quản lý nguồn nhân lực ở tỉnh Phú Thọ còn thấp. Chất lượng nguồn nhân lực làm cho khả năng cạnh tranh của các ngành kinh tế và lao động ở tỉnh Phú Thọ thấp. Đó là một thách thức to lớn của tỉnh trên con đường phát triển và hội nhập.

Ba là, hệ thống cơ chế, chính sách chưa thực sự đưa ra những giải pháp khả thi để gắn giữa đào tạo với phân bổ và sử dụng nguồn nhân lực. Trong nền kinh tế hiện đại, thị trường lao động hình thành, phát triển và hoạt động theo những quy luật khách quan và đòi hỏi phải đổi mới trong chính sách đào tạo nguồn nhân lực; phải gắn giữa đào tạo nguồn nhân lực với cầu lao động trên thị trường nhằm đáp ứng các yêu cầu về số lượng, chất lượng và cơ cấu nguồn nhân lực.

Bốn là, thách thức lớn nhất của tỉnh Phú Thọ là chưa có chính sách và giải pháp vừa cơ bản, lâu dài, vừa cấp bách trước mắt nhằm tuyển dụng lao động.
Hàng năm, tỉnh Phú Thọ phải giải quyết việc làm mới cho một lực lượng lao động rất lớn, giảm cơ cấu lao động nông nghiệp, tăng cơ cấu lao động công nghiệp, xây dựng và dịch vụ. Vì vậy, tỉnh Phú Thọ phải có công cuộc cách mạng về quản lý nguồn nhân lực và phân công lại lao động trong toàn tỉnh. Đây là một thách thức to lớn đối với tỉnh Phú Thọ trên con đường $\mathrm{CNH}-\mathrm{H} Đ H$ và hội nhập.

Năm là, nâng cao tính khả thi của các chính sách phát triển nguồn nhân lực gắn với cải cách hành chính cũng là vấn đề bức xúc. Một khi rào cản về cơ chế, chính sách, pháp luật về phát triển nguồn nhân lực được xóa bỏ thì vấn đề còn lại là khâu tổ chức thực hiện. Nhiều khi đây lại là rào cản không nhỏ, thậm chí quyết định trong chính sách phát triển nguồn nhân lực do bộ máy quan liêu, hành chính tiêu cực và tham nhũng gây ra.

Sáu là, năng lực của cán bộ làm công tác quản lý và phát triển nguồn nhân lực chưa đáp ứng được yêu cầu, nhiệm vụ đặt ra. Một bộ phận cán bộ, công chức sa sút, thoái hóa về đạo đức, quan liêu, cửa quyền, tham nhũng, lãng phí trong bộ máy nhà nước vẫn diễn ra. Trong những năm gần đây, đội ngũ công chức làm công tác quản lý nguồn nhân lực ở tỉnh Phú Thọ đã có những bước trường thành nhất định, phần nào đáp ứng dần những yêu cầu, nhiệm vụ của thời kỳ đổi mới, song cũng bộ lộ nhiều mặt hạn chế, yếu kém, bất hợp lý về số lượng, chất lượng, cơ cấu.

\subsection{Nguyên nhân của nhũ̃ng tồn tại, hạn chế}

Thư nhất, cơ chế quản lý kinh tế xã hội cũ chưa mất hẳn, thể chế chính sách mới được xác lập nhưng chưa thực sự đi vào cuộc sống một cách cơ bản, toàn diện, đã làm ảnh hưởng đến việc thực thi các chính sách, trong đó có chính sách phát triển nguồn nhân lực trong thời kỳ mới. Cơ chế, chính sách không đồng bộ, chưa sát với thực tế, thiếu tính khả thi và chưa tạo động lực mạnh để phát triển.

Thư hai, tình hình chính trị, kinh tế, xã hội trong và người địa phương có nhiều diễn biến phức tạp, trong khi đời sống kinh tế, xã hội còn nhiều khó khăn đã tác động, ảnh hưởng đến tư tưởng, nhận thức và hành động của đội ngũ cán bộ, công chức làm công tác quản lý, chính sách. Chưa nhận thức đầy đủ về sự đổi mới vai trò, chức năng của nhà nước và quản lý kinh tế trong điều kiện chuyển đổi đời sống kinh tế, xã hội của địa phương nên còn lúng túng, bị động trong chiến lược phát triển nguồn nhân lực đáp ứng yêu cầu của thời kỳ đổi mới. 
Thư $b a$, công tác tổ chức, thực hiện các Nghị quyết của Đảng, pháp luật của Nhà nước chưa nghiêm, kém hiệu lực, hiệu quả. Sự lãnh đạo, chỉ đạo, điều hành có phần thiếu nhanh nhạy, chưa thực sự chủ động. Nhiều nhiệm vụ công tác lớn đã được đề ra nhưng thực hiện không đến nơi đến chốn. Một số quan điểm, chủ trương chưa rõ, chưa có nhận thức thống nhất và chưa được thông suốt ở các cấp.

Thư tu, việc quản lý nhà nước về phát triển nguồn nhân lực ở tỉnh Phú Thọ hiện nay chưa kịp với thực tiễn và nhu cầu phát triển khi nền kinh tế đang từng bước chuyển mình sang nền kinh tế thị trường; chưa có sự phối hợp tốt và sử dụng có hiệu quả nguồn nhân lực của nhà nước và xã hội; chậm đổi mới cả về tư duy và phương thức quản lý; chậm đề ra các định hướng chiến lược và các chính sách vĩ mô đúng đắn để xử lý mối tương quan lớn giữa quy mô, chất lượng và hiệu quả trong phát triển nguồn nhân lực; năng lực của đội ngũ cán bộ làm công tác quản lý nguồn nhân lực chưa được chú trọng nâng cao.

Thứ năm, thông tin thị trường lao động không đầy đủ; thiếu sự gắn kết giữa các cơ sở đào tạo với doanh nghiệp, sự tham gia của doanh nghiệp vào đào tạo nhân lực còn hạn chế.

3.3. Các giải pháp hoàn thiện chính sách phát triển nguồn nhân lục đáp úng nhu cầu cách mạng công nghiệp 4.0 tù̀ thục tiễn tỉnh Phú Thọ

Một là, giải pháp về kế hoạch hóa nguồn nhân lục

Tiếp tục hoàn chỉnh thể chế thị trường lao động theo hướng bảo đảm hài hòa lợi ích của người lao động và người sử dụng lao động. Đẩy mạnh công tác đào tạo nghề cho lao động, nhất là lao động nông thôn. Đổi mới hệ thống bảo hiểm xã hội theo hướng đa dạng hóa hình thức và phù hợp với kinh tế thị trường; xây dựng chế độ bảo hiểm thất nghiệp, thực hiện tốt chế độ bảo hộ lao động, an toàn lao động và vệ sinh lao động.

Thực hiện chính sách bảo hiểm xã hội, bảo hiểm thất nghiệp cho người lao động, đồng thời tuyên truyền, vận động nhân dân tham gia bảo hiểm tự nguyện.

Ban hành chính sách thu hút các thành phần kinh tế, đặc biệt là đầu tư nước ngoài, đầu tư vào những lĩnh vực mà tỉnh Phú Thọ có lợi thế, tiềm năng phát triển như: công nghiệp, thương mại dịch vụ, du lịch...

Để hỗ trợ các chính sách trên, cần chú trọng việc cải thiện nhanh việc giải quyết các thủ tục đầu tư, chính sách trợ giá, giải tỏa đền bù đất đai, hỗ trợ tiền thuê đất, cung ứng và đào tạo lao động, xây dựng nhà ở cho công nhân, đảm bảo cơ sở hạ tầng kỹ thuật, chính sách tháo gỡ khó khăn cho các nhà đầu tư... trên cơ sở phù hợp với quy định của pháp luật và trong thẩm quyền của thành phố.

Ban hành chính sách tập trung xây dựng nhanh các khu, cụm công nghiệp, trung tâm thương mại làm tiền đề phát triển nhanh tỷ trọng khu vực kinh tế công nghiệp, xây dựng và dịch vụ, sử dụng lao động phi nông nghiệp ngày càng nhiều.

Tổ chức tốt các hội chợ lao động và việc làm nhằm tạo điều kiện cho người lao động có nhiều cơ hội tìm kiếm việc làm và các doanh nghiệp có nhiều cơ hội tuyển dụng lao động phù hợp với yêu cầu của mình.

Xây dựng mạng lưới thông tin thị trường sức lao động từ cấp xã, huyện. Quy hoạch và hình thành mạng lưới trung tâm giới thiệu việc làm ở tỉnh Phú Thọ.

Hình thành hệ thống thông tin cung cầu nguồn lao động có trình độ cao kết nối với hệ thống thông tin thị trường lao động trong toàn tỉnh.

\section{Hai là, giải pháp về tuyển chọn nguồn nhân lục}

Sử dụng các phương pháp thu hút nguồn nhân lực chất lượng cao phù hợp với khả năng, điều kiện của cơ quan và nhu cầu, nguyện vọng của các đối tượng từ nguồn nhân lực chất lượng từ nước ngoài trở về có thể sử dụng nhiều hình thức. Trường hợp cơ quan, đơn vị cần vị trí việc làm lâu dài thì cần có chính sách và biện pháp để thu hút, tuyển dụng nhằm sở hữu người có năng lực phù hợp. Đối với trường hợp không có nhu cầu hoặc không đủ khả năng sở hữu nguồn nhân lực chất lượng đó nên có cơ chế thu hút, cộng tác thích hợp nhằm sử dụng nguồn nhân lực chất lượng cao phục vụ công việc của cơ quan, đơn vị. Trường hợp này chỉ thích hợp với việc xây dựng và hoàn thiện các dự án quan trọng khi cơ quan không có khả năng sở hữu người có tài năng thì nên cộng tác với họ để hoàn thành dự án quá phức tạp của cơ quan, đơn vị mình.

Xây dựng các tiêu chí đánh giá và quy trình sàng lọc nguồn nhân lực chất lượng. Các tiêu chí đánh giá nguồn nhân lực chất lượng cao phải cụ thể, gắn với nhiệm vụ, vị trí công việc được giao, sát hợp với yêu cầu, đặc điểm của cơ quan, đơn vị. Đồng thời phải áp dụng quy trình thử thách, sàng lọc người có tài năng rõ ràng, công khai, minh bạch.

Ba là, giải pháp về bố trí, sử dụng nguồn nhân lupc 
Bố trí, sử dụng nguồn nhân lực là việc hình thành và phân phối nguồn nhân lực vào các lĩnh vực, vị trí, nhiệm vụ công tác nhằm sử dụng đầy đủ $\mathrm{v}$ à có hiệu quả nguồn nhân lực. Với ý nghĩa như thế, các giải pháp cơ bản dược đặt ra trong việc bố trí, sử dụng nguồn nhân lực cụ thể như sau:

- Dự báo được số lượng nhu cầu nguồn nhân lực. Dự báo sự biến động tăng hay giảm của các bộ phận, nhu cầu về trình độ với các kỹ năng và chuyên môn cần thiết của các công việc cụ thể.

- Tất cả các lãnh đạo UBND tỉnh Phú Thọ phải chịu trách nhiệm về công tác bố trí nguồn nhân lực trên địa bàn mình quản lý. Phải xuất phát từ việc phân tích công việc, mô tả tiêu chuẩn công việc và chủ động chuẩn bị cho mình nguồn nhân lực đảm bảo đúng người đúng việc.

- Xây dựng quy chế về bố trí, sử dụng nguồn nhân lực trong từng cơ quan, tổ chức. Thực hiện nghiêm túc, hiệu quả các quy trình, quy chế về công tác quản lý nguồn nhân lực, nhất là quy định, quy chế về tuyển chọn, đào tạo, bồi dưỡng, nhận xét, đánh giá nguồn nhân lực... làm cơ sở cho việc bố trí, sử dụng có hiệu quả lực lượng nguồn nhân lực. Mạnh dạn đưa vào quy hoạch và xem xét bổ nhiệm nguồn nhân lực trẻ có năng lực công tác, tạo môi trường làm việc cho nguồn nhân lực yên tâm công tác, phục vụ và cống hiến lâu dài cho tổ chức.

- Thường xuyên tiến hành rà soát, đánh giá việc bố trí, sử dụng nguồn nhân lực trong tổ chức, trên cơ sở đó để bố trí, sắp xếp lại cho phù hợp với yêu cầu, nhiệm vụ, năng lực, sở trường, trình độ đào tạo của nguồn nhân lực. Hạn chế việc bố trí lực lượng nguồn nhân lực không phù hợp với chuyên môn được đào tạo.

- Tăng cường công tác đào tạo, bồi dưỡng nâng cao chất lượng nguồn nhân lực; có chính sách khuyến khích, tạo điều kiện cho nguồn nhân lực được đi học, nâng cao trình độ chuyên môn, nghiệp vụ, tạo điều kiện cho lực lượng này đi học tập, nghiên cứu ở trong và ngoài nước.

- Thường xuyên tiến hành sơ kết, tổng kết về lý luận, thực tiễn định kỳ hàng tháng, tháng quý, hàng năm về việc bố trí sử dụng nguồn nhân lực, đánh giá đúng những mặt được, mặt chưa được, kịp thời rút ra bài học kinh nghiệm.

Bốn là, giải pháp về đào tạo, bồi duỡng nguồn nhân lục

Hợp tác quốc tế trong đào tạo là hình thức liên kết đào tạo giữa nhiều nước và vùng lãnh thổ. Đào tạo hợp tác quốc tế phối hợp hoạt động giáo dục đào tạo để thúc đẩy sự phát triển về chất và lượng của giáo dục. Hoạt động đào tạo hợp tác quốc tế đang diễn ra mạnh và trong lĩnh vực đào tạo đại học và sau đại học. Hiện nay các trường đại học ở nước ta đều có liên kết đào tạo với nước ngoài. Hợp tác quốc tế trong đào tạo và nghiên cứu khoa học được coi là chìa khóa trong hội nhập và phát triển nguồn nhân lực.

Đẩy mạnh xã hội hóa các hoạt động giáo dục, đa dạng hóa các loại hình trường, lớp; chú trọng các hoạt động khuyến học khuyến tài, xây dựng xã hội học tập, mô hình công dân học tập suốt đời, đáp ứng nhu cầu, quyền được học tập của nhân dân, nhất là đồng bào các dân tộc thiểu số, vùng sâu, vùng xa.

Có chính sách huy động nguồn đóng góp từ phía doanh nghiệp cho đào tạo nghề, chính sách khuyến khích thành lập các trung tâm đào tạo có chất lượng cao.

Khuyến khích các doanh nghiệp, hiệp hội doanh nghiệp, các cơ sở sản xuất, kinh doanh và nhân dân có khả năng và điều kiện đưa lao động hoặc con em mình đi đào tạo, học tập ở nước ngoài sau đó trở về làm việc.

Đẩy mạnh đào tạo theo đơn đặt hàng của doanh nghiệp và theo nhu cầu xã hội. Phát triển các mô hình, hình thức phối hợp, hợp tác và hỗ trợ đào tạo; thiết lập và phát triển quan hệ hợp tác giữa đơn vị đào tạo và dạy nghề, giữa cơ sở đào tạo với các tổ chức sử dụng lao động trên địa bàn tỉnh thông qua việc ký hợp đồng đào tạo theo nhu cầu. Tăng cường hợp tác và liên kết trong đào tạo nguồn nhân lực với các trường đại học có năng lực và uy tín để đào tạo nhân lực chất lượng cao.

Thu hút đầu tư nước ngoài, khuyến khích xã hội hóa trong công tác phát triển nhân lực trên địa bàn tỉnh. Khai thác, sử dụng hiệu quả các nguồn vốn ODA, NGO, vốn tín dụng thương mại ưu đãi phục vụ lĩnh vực giáo dục và đào tạo, khoa học - công nghệ. Tận dụng các cơ hội đào tạo nhân lực trình độ cao của các tổ chức trong nước và quốc tế.

Tiếp tục duy trì, phát triển và sử dụng có hiệu quả các nguồn quỹ hỗ trợ khoa học kỹ thuật, quỹ khuyến học, khuyến tài Đất Tổ. Tăng cường khuyến khích thành lập quỹ khuyến học, khuyến tài các đơn vị trên địa bàn Tỉnh. Tiếp tục đầu tư hỗ trợ, tập trung đổi mới, nâng cao chất lượng hiệu quả hoạt động của các trung tâm học tập cộng đồng tại các xã, phường, thị trấn.

Năm là, giải pháp về đãi ngộ đối với nguồn nhân luc 
- Hoàn thiện hệ thống trả lương hợp lý, trên cơ sở kết hợp giữa lương cơ bản và các khoản lương phụ cấp. Lương cơ bản là phần lương cứng trả theo cấp bậc công việc, được áp dụng đối với tất cả người lao động trong biên chế của cơ quan hoặc làm việc theo chế độ hợp đông. Phụ cấp là phần lương mềm mà đơn vị trả cho người lao động tùy theo hiệu quả công việc và mức độ đóng góp thực tế của người lao động được trích từ quỹ khen thưởng phúc lợi của cơ quan theo quy định của Chính phủ. Hai loại lương này có quan hệ hỗ trợ nhau và phải đảm bảo tỷ lên hợp lý trong cơ cấu lương. Lương cơ bản phải chiếm tỷ lệ vừa đủ khiến người lao động yêu tâm làm việc cho dù có thể có biến động của môi trường bên ngoài và bên trong cơ quan. Phần lương biến đổi sẽ có tác dụng khuyến khích họ làm việc tích cực và đạt kết quả cao. Nếu lương cơ bản chiếm tỷ trọng nhỏ và thấp đến mức không đủ đảm bảo cuộc sống tối thiểu thì cũng không đủ tạo tâm lý ổn định cho người lao động; trong khi đó lương biến đổi quá lớn và quá khác biệt nhau giữa những người lao động sẽ tạo nên những mâu thuẫn không đáng có giữa họ. Ngược lại, nếu phần lương cơ bản quá lớn sẽ khiến phần lương biến đổi không phát huy được tác dụng khuyến khích của nó.

- Đổi mới chính sách đãi ngộ: cần có chính sách đãi ngộ một cách thỏa đáng thì mới khai thác được tiềm năng của nguồn nhân lực trong quá trình hoạt động công việc. Tạo điều kiện làm việc tốt nhất cho đội ngũ nhân lực như cung cấp thông tin, trang thiết bị hiện đại kết hợp giải quyết thỏa đáng các loại lợi ích vật chất và tinh thần.

\section{Kết luận}

Nguồn lực về con người luôn là yếu tố cơ bản, quan trọng nhất quyết định sự phát triển đối với mọi hình thái kinh tế xã hội. Ở tỉnh Phú Thọ, nguồn nhân lực là nội lực cơ bản nhất, động lực không thể thiếu và là nhân tố quyết định sự thắng lợi của sự nghiệp công nghiệp hóa, hiện đại hóa đất nước.

Trong giai đoạn đẩy mạnh $\mathrm{CNH}-\mathrm{H} Đ H$ đất nước và hội nhập quốc tế, việc nâng cao chất lượng dân số và phát triển nguồn nhân lực là một trong những trọng điểm của chiến lược phát triển đất nước, là chính sách xã hội cơ bản, là hướng ưu tiên hàng đầu trong toàn bộ chính sách phát triển kinh tế xã hội của thành phố. Hệ thống chính sách hiện hành của tỉnh đã tạo sự phát triển vượt bậc cả về số lượng và chất lượng nguồn nhân lực so với những năm trước. Tuy vậy, các chính sách vẫn chưa đủ mạnh chưa thực sự tạo động lực hấp dẫn thu hút nguồn nhân lực, đặc biệt là nguồn nhân lực chất lượng cao.

Tỉnh Phú Thọ có một nguồn nhân lực dồi dào nhưng tỷ lệ lao động được đào tạo kỹ thuật chuyên môn còn thấp, phần lớn là lao động thủ công. Cơ cấu nguồn nhân lực còn lạc hậu. Để có một nguồn nhân lực tốt đáp ứng được những yêu cầu của xã hội trong thời kỳ đổi mới của đất nước, tỉnh Phú Thọ đã không ngừng cải tiến, sửa đổi, bổ sung những chính sách phát triển nguồn nhân lực trên địa bàn thành phố nhằm đưa ra một hệ thống cơ chế chính sách đúng đắn, hợp lý phù hợp với từng thời kỳ phát triển. Chính sách phát triển nguồn nhân lực của tỉnh trong thời gian tới cần được đổi mới theo hướng tạo điều điện thuận lợi hơn cho sự phát triển nguồn nhân lực, đặc biệt là nguồn nhân lực chất lượng cao.

\section{REFERENCES}

1. Academy of Public Administration (2011), Curriculum of state administrative personnel, Statistics Publishing House;

2. Pham Minh Hac (2003), Entering the 21st century, developing human resources to serve industrialization and modernization of the country, Workshop on human resource development KX05011 in Ho Chi Minh City on 22nd / 3/2003;

3. Decision No. 27/2011 / QD-UBND dated November 28, 2011 on approving the planning for human resource development in Phu Tho province for the period 2011-2020;

4. Hoang Phe (2016), Vietnamese Dictionary, Statistical Publishing House;

5. People's Committee of Phu Tho province (2016), Plan No. 3906 / KH-UBND dated September 8, 2016, the provincial People's Committee signed to promulgate Plan No. 3906 / KH-UBND on implementing breakthroughs in human resource development. force of Phu Tho province in the period 2016-2020;

6. Vu Cao Dam (2009), Collection of published works of author Vu Cao Dam, Volume 2: Research on strategy and policy, The Gioi Publishing House, Hanoi; 


\section{THE SOLUTIONS TO IMPROVE POLICIES TO DEVELOP HUMAN RESOURCES IN PHU THO PROVINCE}

\section{Article info}

Recieved:

28/4/2020

Accepted:

20/9/2020

Keywords:

Human resources, Phu

Tho, policy.

\begin{abstract}
With the desire to provide a human resource to meet the requirements in the new period, it is necessary to study the Human Resource Development Policy to meet the needs of industrial revolution 4.0, from the reality of Phu Tho province, The author gives an overall picture of human resource development policies in Phu Tho recently, assessing the shortcomings and finding the causes of those limitations, thereby proposing some solutions to well implementing human resource development policies to meet the requirements of the 4.0 revolution.
\end{abstract}

